\title{
Un acercamiento a las prescripciones dietéticas religiosas y su influencia en la alimentación occidental
}

\section{An approach to religious dietetic prescrip- tions and their influence in western nutrition}

\begin{abstract}
KENDRA CARRIÓN VIVAR Universidad Iberoamericana Ciudad de México, México
\end{abstract}

kdcarrionvivar@gmail.com

Artículo de investigación

Recepción: 13 de enero de 2020

Aceptación: 27 de marzo de 2020

\section{Como citar este artículo}

Carrión, K. (2019). Un acercamiento a las prescripciones dietéticas religiosas y su influencia en la alimentación occidental. Sosquua 1(2), pp. 44-64. Recuperado a partir de: http://cipres.sanmateo.edu.co/index.php/sosquua 


\title{
Resumen:
}

El presente trabajo revisa los preceptos dietéticos de las religiones del libro con el objetivo de evaluar hasta qué punto se han convertido en los ejes centrales de la alimentación actual. Lo anterior, a través de la revisión de la tipificación de la gula y la culpa cristiana; la obsesión del judaísmo con determinar qué alimentos son buenos y malos, y la concepción islámica de la importancia de regular las porciones y alinear los alimentos con las emociones. En este sentido, se revela la importancia del estómago en la concepción y consecución de la virtud, tanto en apego estricto a la religión como en la actualidad. De esta forma, se constata cómo el énfasis realizado en el control calórico y la actividad física (para lograr el ideal delgado en la actualidad) tiene orígenes religiosos más que médicos. Además, cómo esta fijación con la delgadez se da en el marco de una sociedad capitalista que exige control en medio del exceso que, a su vez, conllevan al surgimiento de desórdenes alimenticios y mentales.

Palabras Clave: Dietética; religión; alimentación occidental; desórdenes alimenticios; dieta.

\begin{abstract}
Abstrac:
This paper reviews the dietary precepts of the three (3) religions of the book so as to evaluate the extent in which they have become central axes of the current conception of healthy nutrition. Through the review of the typifying of gluttony and guilt in Christianity; Judaism's obsession with determining which food is good or bad, and the Islamic conception of the value of regulating portions and aligning food with emotions. This work reveals the importance of the stomach in the conception and achievement of virtue, both in adherence to religion and our time. In this sense, we verify how the emphasis placed on caloric control and physical activity (to achieve the skinny ideal of beauty) has religious origins rather than medicals. We conclude that this fixation with thinness occurs within the framework of a capitalist society that requires control amid excess, giving space to increasing eating and mental disorders.
\end{abstract}

Key words: Dietary; religion; western nutrition; eating disorders; diet. 


\section{Introducción}

Pensar actualmente en una dieta resulta casi "natural". En algún punto u otro, por salud o por vanidad, haberse adscrito a un régimen alimenticio se convirtió en una especie de rito de pasaje en la búsqueda de encajar con el ideal de belleza instaurado en nuestra época (Stearns, 2002; Aamodt, 2002; O’Neill \& Silver, 2016). La belleza, considerada como un valor, ahora se mide en términos de delgadez, de un determinado índice de masa corporal, de un cierto porcentaje de grasa... (Hoverd, 2011; Brierley, et al., 2016). Para llegar a ello es imperativo combinar dos (2) elementos centrales: la dieta y el ejercicio. Sin embargo, al revisar las principales exigencias de los regímenes actuales, es posible constatar cómo están relacionadas con varios preceptos de las religiones del libro: cristianismo, judaísmo e islam. A través de la revisión de los principios dietéticos de estas religiones, el presente artículo busca develar cómo los ejes que guían la alimentación actual en occidente en realidad están basados en las máximas de estas religiones, incluyendo los sentimientos de culpa, la categorización de alimentos buenos y malos, y el cálculo de las porciones. Posteriormente se ofrece una reflexión respecto al impacto que estas tienen en la actualidad y cómo, de alguna forma, se las ha llevado a extremos para convertir el culto al cuerpo en la religión predominante en nuestra época, y al gimnasio en su iglesia.

\section{La gula cristiana}

Aunque el cristianismo no prohíbe el consumo de ningún alimento per se, existe un código dietético que busca orientar a los fieles y recordarles la importancia de la moderación en la ingesta de comida. Como muchas de las prescripciones del cristianismo, este código está tipificado como un pecado y, para el caso específico de la comida, es la gula. Sin embargo, a diferencia de cualquier otra falta que puede ser corregida por medio del arrepentimiento, la gula se encuentra clasificada entre los vicios capitales, los cuales abren paso a la comisión de otras inmoralidades.

En su texto La Gula, Tomás de Aquino (1998) se cuestiona cómo identificar el momento en que estamos pecando cuando el alimentarse corresponde a una necesidad biológica antes que al placer. En esta línea aclara que, en sí, la apetencia de comer o beber no consiste en el 'enemigo interno' (la gula), sino solo aquella 
gana 'desordenada' que se aparta del orden de la razón. Por ello, afirma que el excesivo apego a los alimentos mancha espiritualmente al hombre, más aún cuando se desean los alimentos de forma irracional y se excede en su consumo de forma consciente, guiados por el placer que producen los manjares (De Aquino, 1998).

Para sostener esta tesis, se explica que existen dos (2) tipos de apetito: "el natural, en el que no cabe el vicio y el sensitivo, que produce ese deseo desordenado por comer" (De Aquino, 1998, pp. 439-440). En apego a la tradicional visión católica, se asocia a los sentidos como algo negativo que va en contra de Dios; reproduce el pecado original en donde Adán y Eva prefirieron dar deleite a los sentidos por medio del consumo del fruto prohibido, desobedeciendo y olvidándose de Dios. Por ello, es comprensible que la gula pase a ser considerada como un pecado mortal; hace que el hombre "pierda todos los méritos de comportarse bien" al privilegiar el deleite propio sobre el amor a Dios (De Aquino, 1998, p. 440).

La identificación del estómago como un órgano que nubla el comportamiento racional del hombre se puede trazar a la antigua Grecia, en donde filósofos como Hipócrates o Plutarco recalcaron la importancia de dominar el vientre a efectos de conservar la salud y, por este medio, la virtud (Hipócrates, 1987; Plutarco, 2018). En el caso de Tomás de Aquino, la incapacidad de dominar el estómago vuelve al individuo más proclive de incurrir en otros pecados, alejándolo más y más de Dios. Es importante notar que, para el cristianismo, el amor de Dios es la elección que el individuo debe escoger como fin último por encima de todo. Consideran que su hijo se sacrificó para redimir a toda la humanidad. Por tanto, no es sorprendente que la gula merezca un "castigo severísimo" (De Aquino, 1998).

El problema con este deseo irracional por la comida es que abre espacio a la comisión de otros vicios como la lujuria, la concupiscencia y la soberbia (Tomás de Aquino, 1998). No obstante, De Aquino aclara que la gula es causa accidental y ocasional de estas otras faltas, entonces, no constituye la condición esencial de ellas. Asimismo, se puede dañar al cuerpo como consecuencia de esta búsqueda inmensurable del deleite, atentando contra la creación divina que también es el cuerpo humano. Así, los efectos físicos de la gula, como la indigestión, los dolores de cabeza o la diarrea, pueden entenderse como materializaciones de la culpa, o bien, como un castigo inmediato por haber pecado. 
Figura 1. Clasificación del apetito según Tomás de Aquino

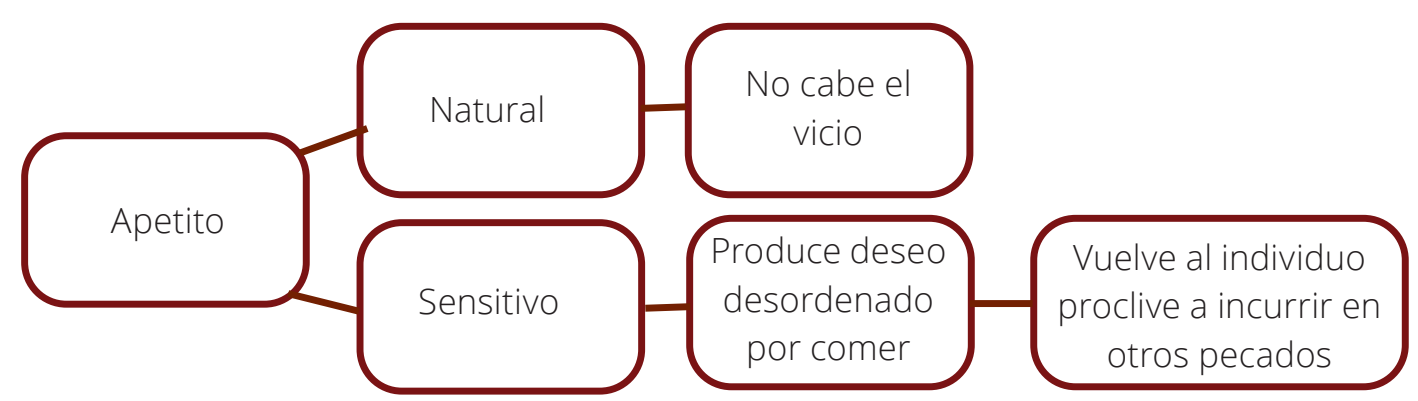

Fuente: Elaboración propia.

Ahora bien, ¿es posible hablar de tipos de gula? Según los preceptos de Tomás de Aquino, más que caracterizar tipos de gula, es imperativo distinguir que el acto de comer está constituido por dos (2) elementos: los alimentos y la acción de tomarlos (De Aquino, 1998). En esta línea, el desorden del deseo surge bajo un doble aspecto: el hecho de desear un alimento rico, abundante, bien preparado, que puede llevar al individuo a excederse en su ingesta simplemente por las cualidades del alimento per se. Por otro lado, el desorden en el acto mismo de tomar el alimento, es decir, comer rápido, sin mostrar ninguna especie de moderación (De Aquino, 1998; Otsuki, 2016).

El hombre busca el deleite porque es una condición de la felicidad, sin embargo, Tomás de Aquino advierte que cuando el deleite es el fin en sí mismo, y no la nutrición del cuerpo o la saciedad de una necesidad, se incurre en pecado. Por tanto, quien desestima la salud, priorizando comer antes que saciarse, peca, pues olvida que la finalidad del deleite es apagar el hambre y la sed (De Aquino, 1998). Es importante notar que, bajo esta concepción, la salud en sí no es el eje central de estas prescripciones, sino que se la entiende como un medio para que el hombre dedique y ofrezca su vida a Dios. 
Figura 2. Cómo se produce el desorden en el acto de comer, según Tomás de Aquino

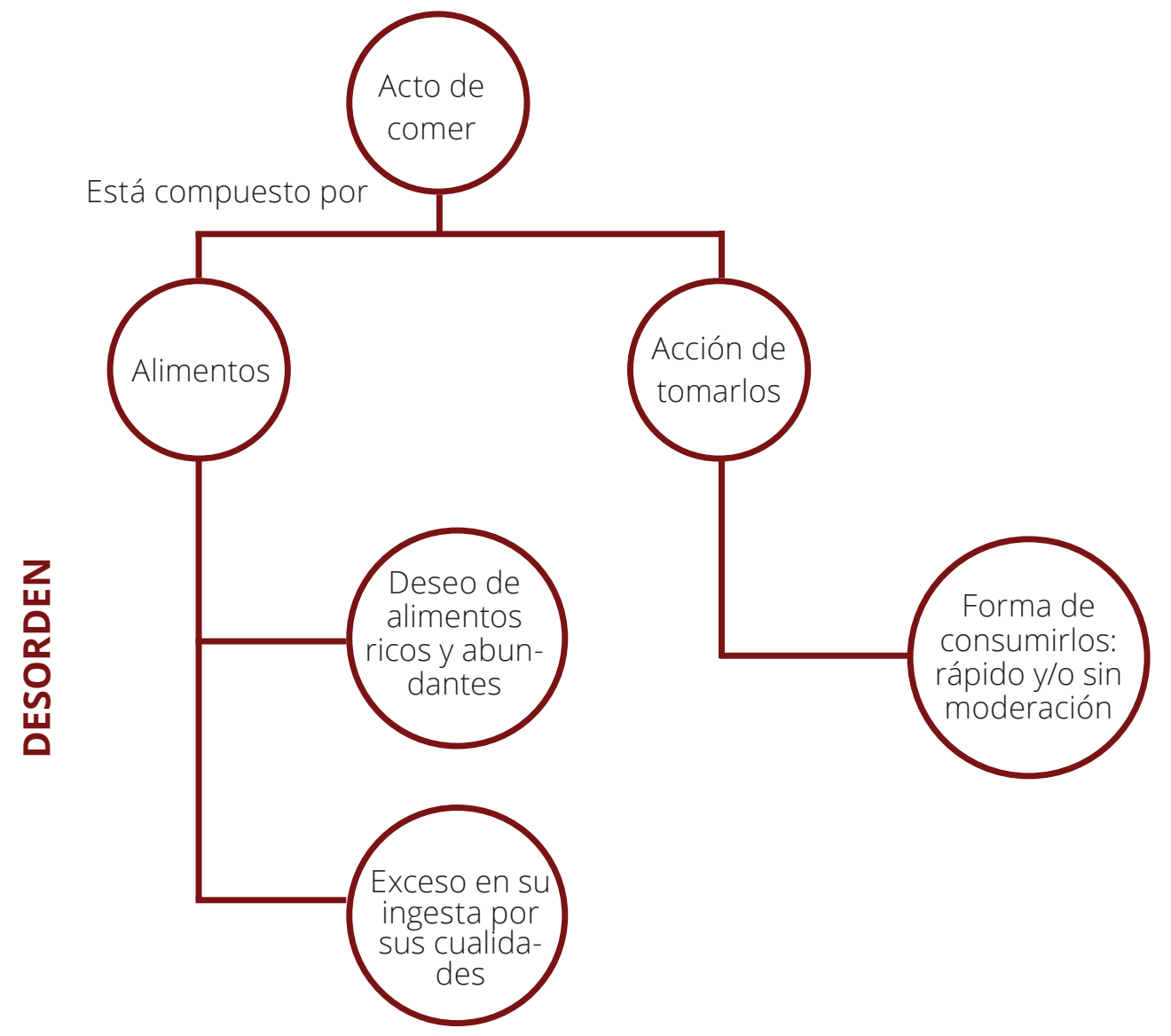

Fuente: Elaboración propia.

Entonces, si se incurre en la gula, ¿cuáles son sus efectos? Además de la ya referida ceguera mental o racional, Tomás de Aquino agrega a la alegría indefinida, la locuacidad, la bufonería y la inmundicia. Por estar dedicado al deleite inmoderado de la comida, la razón se 'embota' y el individuo deja de estar en control de sí (De Aquino, 1998). En consecuencia, se sugiere la abstinencia como un medio para favorecer la agudeza mental, se rechazan las prácticas vomitivas y se disuade del consumo de vino, pues "hace creer que todo es seguridad y gozo" (De Aquino, 1998, pp. 443-444). 
Estos excesos son malos porque vuelven al hombre superfluo y a veces poco honesto, algo que también atenta contra los preceptos del decálogo. La incontinencia del apetito lleva a otras incontinencias libidinosas que se catalogan de inmundas, entre ellas, especialmente, la emisión de semen (De Aquino, 1998). La sexualidad se aparta entonces del carácter dietético que tenía en épocas anteriores, como en Grecia, y se inserta en una lógica cristiana-católica, considerada como un pecado si no se practica en el marco de la institución del matrimonio.

Figura 3. Efectos de la gula

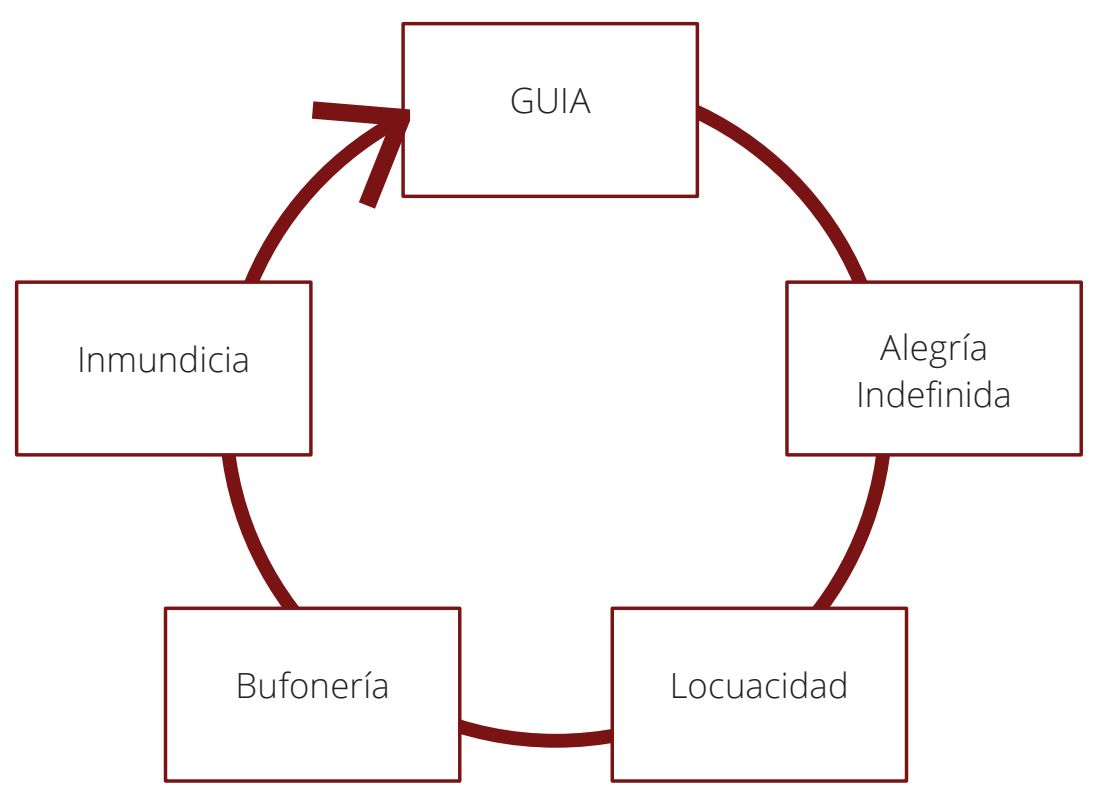

Fuente: De Aquino, T., "Summa Theologica II", 1998.

La tipificación de la gula es útil para entender al cristianismo en el marco de la formulación de algo que en el medioevo devendría una ley. Al cumplir con el mandato de evangelizar el mundo, la comunidad cristiana es una comunidad de la escasez; no era común la abundancia de alimentos, por lo cual ser glotón implicaba impedir que otros pudieran comer. Por tanto, la máxima cristiana era la de comer poco, pero todos, evitando que pocos coman mucho. 
La expansión del catolicismo y la lógica de adaptar la alimentación a nuevos lugares hace que no existan restricciones como en las otras religiones del libro: el alimento bueno es el que se encuentra en el lugar donde se esté (Álvarez, 2019). Más allá de regular el qué comer, se regula el cómo -en comunidad- y con quién compartir -todos, como lo prescribió Jesús-.

En cuanto a la constitución de un marco legal que implicaba que la gula podía ser denunciada y penada, se trata de que la comunidad concientice que, si bien existen momentos en que el individuo puede cometer un exceso por 'error de cálculo', el reincidir implica hacerlo con la conciencia del exceso. Evitar que otros incurran en la gula, por tanto, implica la preservación de la comunidad en sí misma. En esta línea, la culpa es un efecto moral de la apreciación del otro: "no me excedo para que todos podamos comer" (Álvarez, 2019). Sin embargo, es cierto que esta culpa ha evolucionado y permeado de otras formas -y con otros objetivos- a nuestros tiempos.

Asimismo, resulta interesante cómo a diferencia de las otras religiones del libro, así como de la dietética griega, no existe un imperativo de ejercitar el cuerpo. Los cristianos siempre han penalizado el cuerpo; el 'ejercicio' que consideran es del alma, por medio de ritos como la cuaresma. El ejercicio físico se entiende, más bien, como vanidad (Anderson, 2011). Nuevamente, la alimentación y su regulación siempre se entienden como medios para servir a Dios.

Por tanto, para el cristianismo no existen alimentos malos, lo malo es el exceso. Lo que más importa bajo la lógica de esta religión es la manera en que se come: en comunión, como lo hizo Cristo, cuyo cuerpo, además, está simbolizado por el pan. Esta importancia de la comunidad pone énfasis en la reproducción; el origen del mal también se entiende en las líneas de no tener una familia, por lo cual uno de los peligros principales para los cristianos serían los solteros.

\section{La regulación judía}

La discusión sobre la gula cristiana abre la dietética a la relación entre religión y alimentos. En esta línea, los judíos permiten entender la concepción de santidad de los alimentos; se trata de la primera religión que se cuestiona qué productos son correctos para el consumo y cuáles no. A través de una interesante reflexión, Mary Douglas (1973) explica cómo la prohibición alimenticia judía consiste, de hecho, en una forma de distinción. 
El pueblo judío es el primero que codifica la dietética (Álvarez, 2019) y se sirve de este código simbólico para diferenciarse de su entorno. Así, más que prohibiciones en sí mismas, las reglas de la alimentación judía tienen que ver con el respeto a la comunidad: se come de determinada forma para separarse de los otros, para distinguirse. A diferencia del cristianismo, en donde más bien hay una lógica de democratización en la que el pan debe compartirse con todos, para el judaísmo la comida no es para todos, es para aquellos que pertenecen a la comunidad.

¿Cómo se articula esta formulación? Según Douglas (1973), se puede rastrear la prohibición de los alimentos en el enlace entre religión, aquello que se considera santo y el temor. Para los judíos, lo sagrado provee un blindaje simbólico ante la naturaleza, ante la realidad. Lo anterior, considerando que se trata de la gran religión del exilio, el lazo que une a la comunidad judía es el culinario (Álvarez, 2019).

Así, existe comunidad donde se respete a la Torah, donde se coma conforme prescribe la Escritura. Esta visión es tan fuerte que permite entender cómo, finalmente, el pueblo judío no necesita un territorio; es tan disciplinado que lleva sus reglas a todas partes. Por ello, es imperativo cuidar que no se contamine de cualquier cosa, o costumbre, que los pueda rodear.

Se habla de contaminación porque es la higiene el factor que explica estas reglas y, con ellas, la distinción. Lo sucio implica desorden, implica romper con la primera moralización del cosmos (Douglas, 1973). Bajo la lógica del judaísmo, existe una oposición entre su comunidad y los demás. Por ello, han codificado la costumbre en torno a los ritos de pureza, los que a su vez permiten crear unidad en la experiencia: independientemente de donde estén, todos los judíos han experimentado de la misma forma sus ritos y fiestas (Álvarez Solís, 2019).

Figura 4. Ejes de la alimentación judía

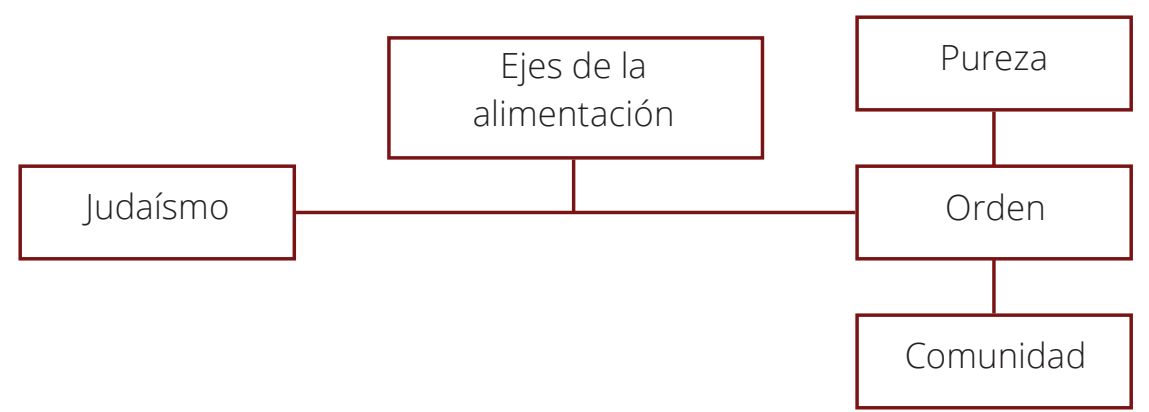

Fuente: Douglas, M., "Pureza y peligro. Un análisis de los conceptos de contaminación y tabú", 1973. 
Ahora bien, si se institucionaliza la pureza, es necesario, como en el cristianismo, tipificar lo malo, lo contaminado. Para los judíos esto comienza con los alimentos, lo cual llama la atención cuando existen comunidades cuyos entendimientos básicos son la familia, la vestimenta o la sangre. Para los judíos, los alimentos son los guardianes que previenen que la comunidad se contamine. Más que un orden interno, se trata de un orden jerárquico hacia el exterior: todos los judíos son iguales, pero superiores al resto (Álvarez, 2019). A diferencia del cristianismo, en donde la exclusión se da en la parte sexual y todo lo malo tiene que ver con los sentidos, los judíos realizan su exclusión por medio de los alimentos. Siempre hay alguien sacrificado y los sacrificados pueden ser los alimentos.

Como se ha mencionado con anterioridad, la comunidad cristiana se caracterizó por la escasez, por lo cual no se discriminan los alimentos y la comunidad se sacrifica solo en ciertas fechas. En contraste, los judíos, que siempre tuvieron ventajas económicas, han sido capaces de seleccionar sus alimentos de acuerdo con las prescripciones religiosas. Por ello existe lo kosher, lo correcto, lo que implica el respeto a la comunidad (Regenstein \& Chaudry, 2003; Álvarez, 2019).

En esta línea, las interpretaciones del Levítico son literales, no alegóricas y, además, se han mantenido constantes en el tiempo (Douglas, 1973). Cuando se conciben a sí mismos como el pueblo de la ley, los judíos también se consideran como el pueblo de la purificación. Así, la santidad es algo inmanente, no es un fin exterior al individuo, está dentro de él. Por ello, el judío se forma en santidad, en respetar las leyes a efectos de hacer parte de la comunidad.

Figura 5. Alimentos prohibidos para el judaísmo

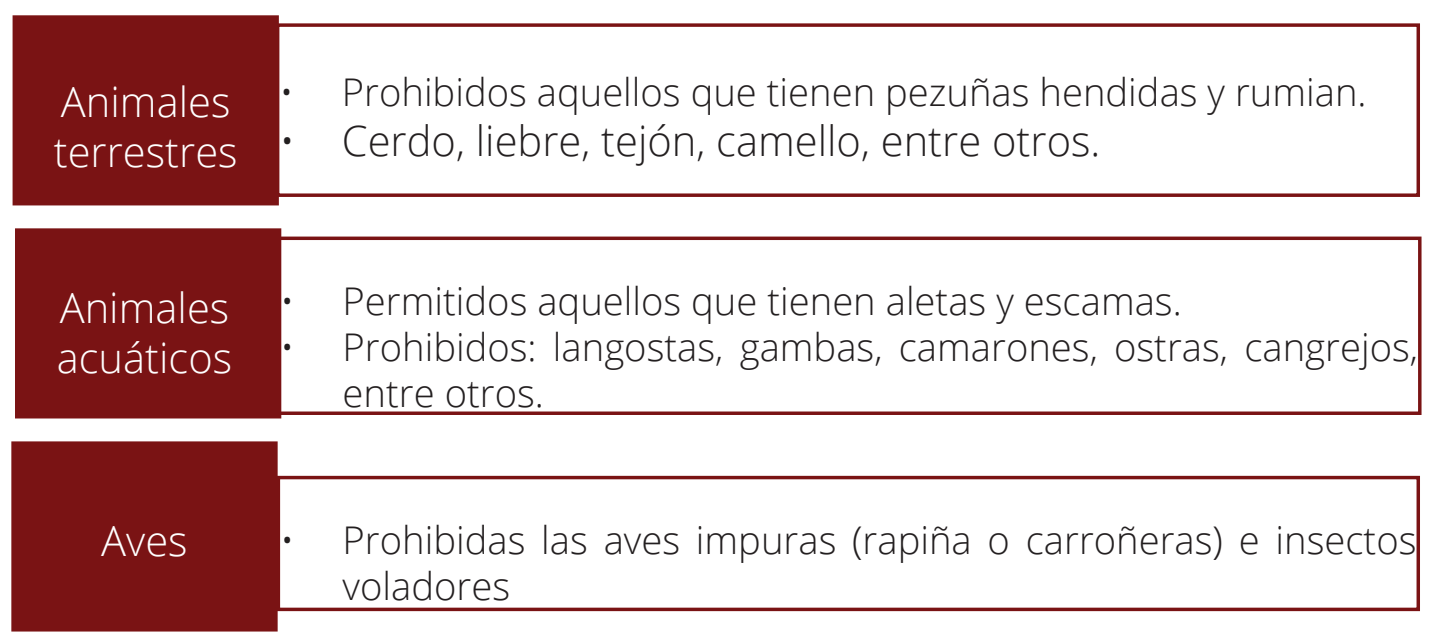

Fuente: Douglas, M., "Pureza y peligro. Un análisis de los conceptos de contaminación y tabú”, 1973. 
Mientras en el cristianismo se ingresa a la comunidad por medio del rito del bautismo, el judaísmo produce comunidad por medio de la dietética, entendido como producción de santidad (Álvarez, 2019). Otra diferencia muy interesante entre ambas religiones es la consideración del tamaño de la comunidad. Los cristianos ven a su comunidad como infinita, como creciente y permanente gracias a la evangelización, por lo que las leyes serían restrictivas y cerrarían a la comunidad, impidiendo su expansión. De otro lado, los judíos entienden a la ley divina como algo interno, como algo que se debe seguir por santidad. No hay nada más judío que la normatividad (Âlvarez, 2019). Vale rescatar que, a diferencia de los cristianos, quienes ejercitan el alma, los judíos tienen una obsesión por la perfección física, la cual reflejaría el cumplimiento de esta santidad; a su vez es un efecto del cumplimiento de las reglas dietéticas, a través de las cuales el judaísmo ha construido un imperio religioso (Álvarez, 2019).

En cada animal prohibido en el judaísmo hay una alegoría respecto a una conducta; se codifica moralmente a los alimentos, porque son sedimentos éticos (Douglas, 1973). Por lo tanto, lo que es más sano para un judío implica que sea lo más puro, lo más limpio, lo más simple. Esta religión teologiza el mundo, por lo cual los alimentos tienen propiedades sagradas (Eliasi \& Dwyer, 2002; Regenstein \& Chaudry, 2003).

Así, lo kosher no es más que la teologización de la comida (Álvarez, 2019). El núcleo de la dietética judía es identificar qué alimento es puro y cuál es impuro, procurar que cada alimento corresponda a su función en el cosmos, en el orden del universo. La concepción comunitaria, por tanto, se basa en un contrato culinario con Dios: si se come cierto tipo de alimentos, todo saldrá bien (Douglas, 1973). No obstante, todos tienen que cumplir con el contrato, porque de lo contrario todo saldrá mal para todos. Por esto, se ofrece una educación estricta sobre la alimentación y su manual es el Levítico.

\section{El dulce gusto islámico}

En lo que puede ser catalogado como el primer tratado sobre dietética, Maimónides (2016) ofrece el entendimiento que el islam tiene sobre el régimen alimenticio (Álvarez, 2019). De hecho, el régimen se asocia con la salud más que con una forma de vida, como lo concebían los griegos. Por ello, con esta novedad, la 
dietética pasa a formar parte de la medicina terapéutica árabe, enfocada en arreglar los cuerpos 'dañados'.

Para los árabes, todo lo que existe en el mundo son cuerpos sensibles, todo tiene un peso, incluso el alma. No es de extrañar, entonces, que el mundo es una suma de cuerpos; cuando se come se ingresa un cuerpo en otro cuerpo y la digestión concluye con la expulsión de otro cuerpo (Álvarez, 2019). La ontología árabe se compone, entonces, de cuerpos livianos, que se mueven por sí mismos, y cuerpos densos, que necesitan de otro cuerpo para moverse.

Para el islam, lo dulce es el alimento más puro (Maimónides, 2016). Las máximas de la religión profética se centran en comer bien; si algo no funciona, se soluciona vía la alimentación, si no es así, entonces se sugiere tomar medicina; si definitivamente no hay solución, optar por una cirugía (Maimónides, 2016). De esta forma, la medicina árabe se codifica de manera dietética, aunque en realidad los tratados de cocina fueron escritos por gobernantes, pues eran considerados modelos a seguir y, por tanto, podrían transmitir sus prácticas al pueblo.

Figura 6. Enfoque islámico de la alimentación como medio de sanación

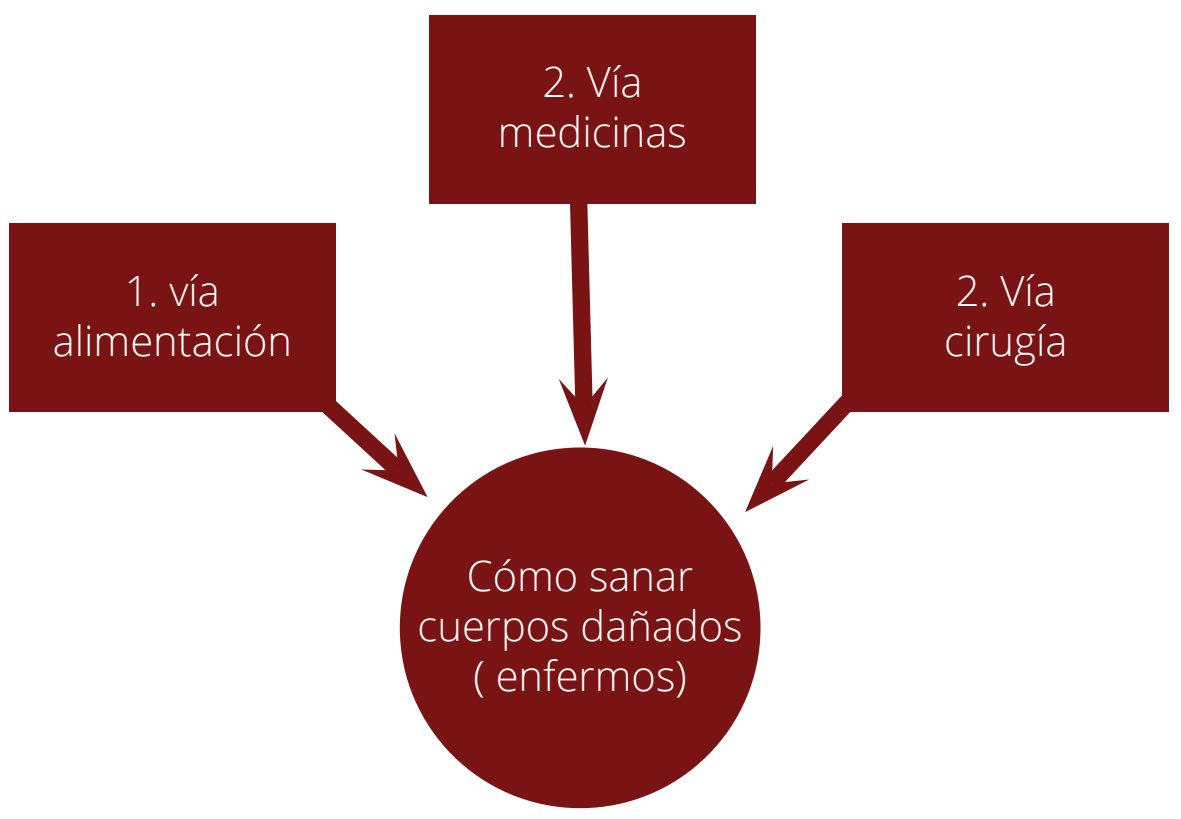

Fuente: Elaboración propia. 
Más que enfocarse en prescribir comida que no enferme, la dietética islámica busca las maneras en cómo se puede comer de manera más esplendorosa (Maimónides, 2014); es la ciencia de la medida, de la porción adecuada. Cualquier alimento se puede consumir mientras sea en la porción adecuada; se deja de lado la moralización, para los árabes la dietética es un conocimiento, no una técnica (Álvarez, 2019). En esta línea, la obligatoriedad de la porción debe cumplir con dos (2) aspectos: la simetría corporal y espiritual. Es decir, los alimentos se alinean con las emociones (itidal); la adecuación de la comida con el momento, no solo el clima, sino lo que sea bueno para las emociones del individuo (muwalia). Así, la suma de ambos elementos produce la salud (sihha) (Álvarez, 2019). Por tanto, estar sano implica mantener las emociones y el cuerpo, y la dietética es la ciencia de la regulación entre las emociones y los alimentos; produce más beneficio físico y emocional, es lo que más alimenta. Por ello, los dulces son lo más puro.

Figura 7. Características de las porciones alimenticias

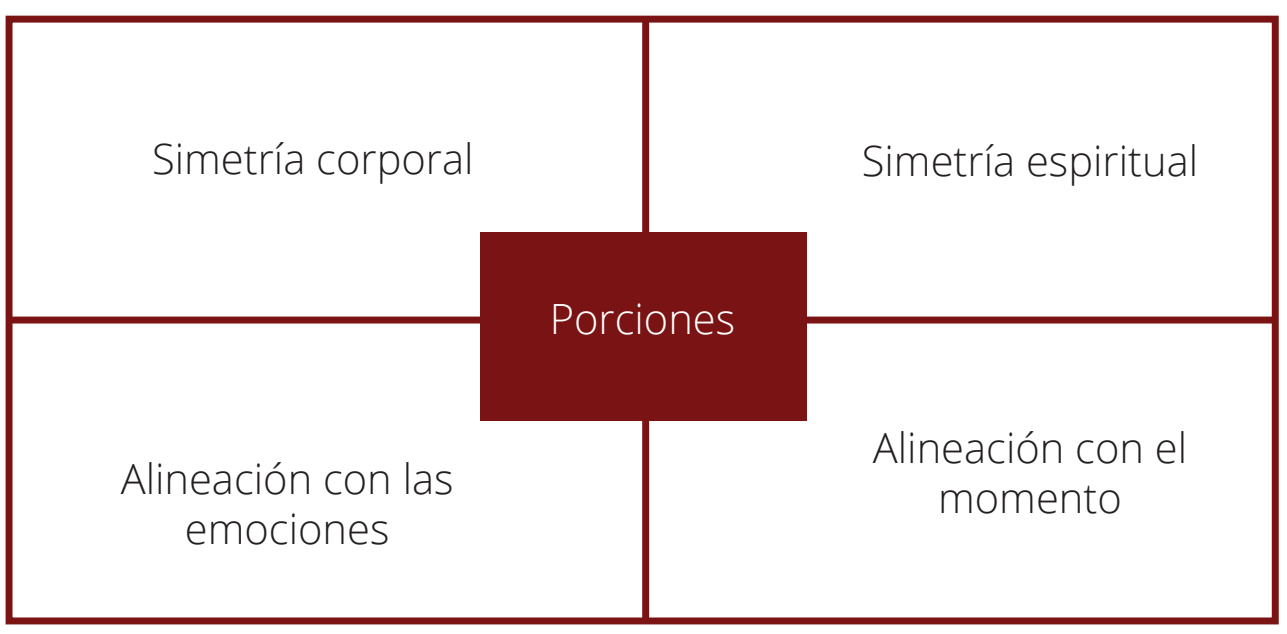

Fuente: Maimónides, "Obras Médicas I", 2014.

La dietética árabe considera la teoría de la al mulqadina; supone que la enfermedad es producto de una mala dieta. Pero ¿qué implica una mala dieta? Corresponde a cualquier cosa que cause malestar, indigestión (Maimónides, 2016). La indigestión es entendida como un efecto de los cuerpos densos; hacen que quien los ingiere se vuelva más denso y menos vital. Así, el estómago es el lugar donde se asientan las enfermedades y la indigestión es la causa de todos los males, incluso 
los morales (Maimónides, 2016). Lo anterior, en un interesante paralelismo con los cristianos. Por lo tanto, las enfermedades se producen por el modo de vida: exceso de especias, porciones muy grandes, falta o exceso de ejercicio o aire no propicio.

En este contexto, el valor del alimento se jerarquiza por su digestibilidad, es decir, que el cuerpo se sienta con energía (elemento que se constata por medio de la consistencia de los alimentos y las heces); en sus cualidades nutricionales y en los efectos biológicos en el cuerpo (Maimónides, 2016). Así, la nutrición se mide en función de la sustancia propia del organismo: mientras más energía ofrezca, más nutritivo; elemento que ratifica el valor de los dulces.

De igual forma, los alimentos producen efectos físicos y anímicos; es necesario verificar los alimentos en función de lo que cada individuo necesita conforme al humor de cada día (Maimónides, 2016). Es importante subrayar que la dietética árabe clasifica las propiedades emocionales de los alimentos en función del sentido que despierta cada uno: vista, tacto, olfato, entre otros (Álvarez, 2019).

Por tanto, el problema central de la dietética árabe es la buena digestión, para lo cual hay que mantener el estómago liviano. La indigestión, más que entenderse como un castigo al estilo cristiano, se entiende como parte de la experiencia culinaria: si se presenta muchas veces implica que no se está entrenando bien al cuerpo. Así, es mejor tener indigestiones reguladas que una mortal (Maimónides, 2016). La obsesión es regular la digestión: es preferible ingerir poca comida mala a mucha comida buena. Todo esto con el objetivo de evitar la inflamación y el estiramiento del estómago.

En conclusión, para la dietética árabe los alimentos no son malos por naturaleza, sino que la clave de comer bien es calcular bien las porciones. Es importante subrayar que, aunque se aconseja el ejercicio físico, se consideraba que su exceso impedía el desarrollo a la mente (mucho peso al cuerpo quita movimiento a la neuma). Por ello, se penalizan a los cuerpos muy trabajados o a los muy delgados. Por último, cabe mencionar que, dado que la dietética influye en el aspecto público, es ahí donde tiene que resolverse. Por ello, los árabes son los inventores de la política alimentaria, ya que codificaron lo que deben comer los gobernantes a efectos de que puedan seguir gobernando y garantizando que todos los ciudadanos tengan acceso a comida (Álvarez, 2019). 


\section{Las prescripciones dietéticas religiosas y la configuración de la alimentación actual}

La revisión de las prescripciones dietéticas de las tres (3) religiones del libro lleva a reflexionar respecto a su validez e impacto en la actualidad. Resulta interesante constatar cómo, más que el seguimiento que los respectivos fieles puedan tener de estas consideraciones, su conjunción guía la alimentación de occidente. Allí existe prácticamente una obsesión respecto a lo que es bueno y lo que es malo, como el judaísmo; respecto al cálculo de las porciones, como el islam; y cómo alejarse de lo light produce sentimientos de culpa, al más puro estilo cristiano (Stearns, 2002).

En efecto, aunque la reificación de los cuerpos delgados es un fenómeno más bien reciente, data de la segunda década del siglo XX (Vigarello, 2011), los rápidos avances tecnológicos y la creciente interconexión del mundo han logrado posicionar un tipo específico de cuerpo ideal y de estilo de vida, independientemente de la región y la cultura (Stearns, 2002; O'Neill \& Silver, 2016). Ahora se aspira a una delgadez que llega a ser antinatural, en el marco de una sociedad constantemente preocupada por las maneras más eficientes de lograr este objetivo (Girard, 2009). Por ello, se han creado diversas dietas, métodos, ejercicios que permitan al individuo insertarse en lo que se considera bello y aceptable (Brierley, et al., 2016).

Sin embargo, se trata de una lucha en la cual, a diferencia de las épocas en donde el cristianismo tipificó la gula, existen amplias opciones para excederse; no solo en la cantidad, sino en el tipo de comida, pues nunca es fácil acceder a gastronomía de lejanos lugares. En esta línea, resulta difícil no sucumbir ante el deseo de comidas ricas y copiosas; en un contexto capitalista en donde el deseo está en constante creación, el individuo es estimulado a ceder ante sus antojos y caprichos, puesto que trabaja arduamente, se lo merece. 
Figura 8. Elementos religiosos insertos en la lógica de la alimentación occidental actual

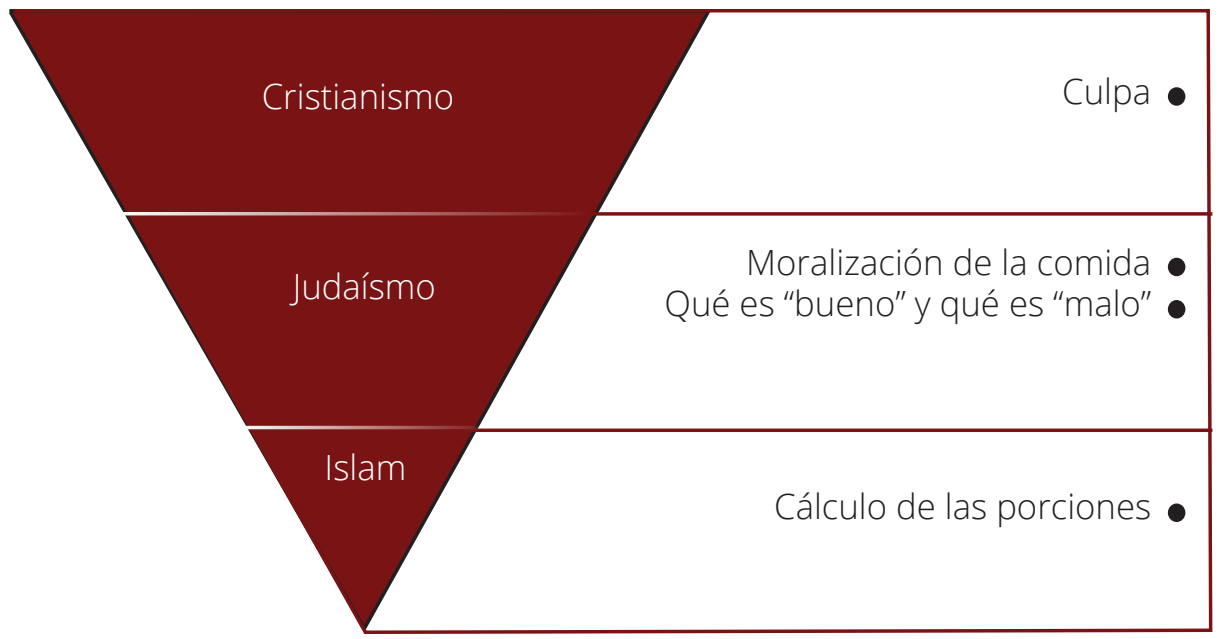

Fuente: Elaboración propia.

Esta comida que se incita a consumir, además, se aleja muchas veces de la lógica nutricional para servir a la industria y, generalmente, es rica en grasas y sal (Aamondt, 2016). La sociedad actual vive en una constante contradicción; se cree preocupada por la salud y la importancia del ejercicio, mientras alimenta irresponsablemente a sectores que, por falta de educación o ingresos, o ambas, solo puede acceder a la comida chatarra. De otro lado, quienes pueden permitirse el lujo de elegir y seleccionar, como los judíos, entran en un círculo de vanidad en donde se atestigua el culto al cuerpo y se enfatiza la necesidad de cultivarse físicamente: ser bello para poder pertenecer.

En este contexto, se penaliza aquello que se aleje de esta normatividad de lo bello y lo deseable. Así, se estigmatiza la gordura como un daño social, pero se empuja a la gente a seguir comiendo. Es como si el sistema fuera una prueba permanente al control: se tiene acceso a un sinnúmero de alimentos, pero se nos exige ser delgados y el resultado de esa autoexigencia se premia con aceptación. En suma, la delgadez, en nuestra época, es una virtud y existe una "militancia contra la gordura" (Vigarello, 2001, p. 251-260; Stearns, 2002; Brierley, et al., 2016).

Esta virtud se cultiva, muy curiosamente, en función de los preceptos religiosos, aún si muchas de las personas que incurran en seguirlos estrictamente se 
declaren como no creyentes. La iglesia de esta época parece ser el gimnasio y, en el marco del dominio de las redes sociales, no hay excusas para no estar activo. De esta forma se ha creado un nuevo mercado dedicado a impulsar a la gente a esforzarse, a convertirse en "la mejor versión de sí mismos".

Además, se constata la existencia de una amplísima variedad de aplicaciones de rutinas de ejercicios, dietas, diarios de comida, entrenadores personales a distancia, entre otros. Si no existe la posibilidad de pagarlos no hay problema. El mercado se abre paso al individuo detrás de una faux democratización a través de videos gratuitos en plataformas como YouTube, que mueven altísimas cantidades de dinero detrás de auspicios, publicidad y la inducción de los usuarios a productos en dichos videos.

Aunque más recientemente se han creado más movimientos de aceptación de los cuerpos, denominados generalmente body positive, lo cierto es que en el fondo esto no ha coadyuvado al cambio de mentalidad, respecto a lo que en realidad se considera bello y el ideal actual: la delgadez. Un 'gordito' puede ser bello, pero no tan bello como alguien delgado. Este parece ser el imperativo de nuestra época, en donde más bien estos movimientos solo señalan las maneras creativas en que el capitalismo se abre a nuevos mercados (Álvarez, 2019).

Al hablar de una sociedad del exceso, no hay que obviar que éstos ocurren de lado y lado; más que nunca se registran desórdenes alimenticios como la anorexia y la bulimia, surgidos como consecuencia de la exigencia del entorno. En ellas, según Girard (2009), no existen motivaciones de estar saludables, solo se trata de adelgazar por adelgazar. Se trataría de un paralelo extraño con los místicos cristianos, quienes pensaban que mientras menos comían se acercaban más a Dios (Anderson, 2011). Las anoréxicas se acercan, con su ayuno, a esa imagen reificada nuestra época.

Lamentablemente, no se trata de una patología exclusiva de un grupo de personas; cada vez con más frecuencia, todos terminamos experimentando versiones atenuadas de estos trastornos. Se ha naturalizado 'sentirse mal' por ganar peso, por no hacer ejercicio, por 'comer mal' un día, por 'comer de más'... De hecho, se puede decir que estas expresiones ya forman parte de un lenguaje y una percepción cotidiana en occidente (Stearn, 2002; Aamond, 2016). 


\section{Conclusiones}

Se han revisado los distintos preceptos dietéticos de las tres (3) religiones del libro a efectos de constatar cómo, de cierta forma, influyen en la manera en que la alimentación se concibe actualmente en occidente. Incluso, cada uno ha sido llevado al extremo, a efectos de conseguir un ideal que para muchos es inalcanzable. A continuación, se realizará una breve recopilación a efectos de proveer unas reflexiones finales.

En el caso de la dietética cristiana, es evidente que, aunque no se prohíbe el consumo de ningún alimento, se tipifica el consumo excesivo por razones sociales y religiosas. En este sentido, la regulación de la ingesta alimenticia se da en el marco de una época de escasez en la cual comer más implicaba que alguien más dejara de comer. Se trata de la religión en donde Jesucristo se sacrificó por toda la humanidad, por todos los tiempos; lo imperativo no es sacrificarse nuevamente, sino compartir; compartir el pan y, con ello, el cuerpo del cordero de Dios. La consideración de la gula como un pecado mortal se ancla en la concepción del estómago como puerta de otros vicios, incluyendo la lujuria y la concupiscencia (De Aquino, 1998).

Como en la antigua Grecia, se asocia a este órgano como capaz de nublar la razón humana y, por tanto, hacer que el individuo incurra en otras faltas. Resulta interesante la tipificación que realiza Tomás de Aquino sobre la gula; siempre está presente el cuestionamiento de hasta qué punto se trata de atender una necesidad biológica y hasta qué punto se da gusto al placer de la carne. Como se ha visto, se ofrece una explicación minuciosa inclinada por demonizar a la complacencia de los sentidos pues evita que el ser humano elija amar a Dios por sobre todas las cosas.

En esta línea, la culpa cristiana se mantiene muy presente en la actualidad, aunque con otras justificaciones. En el marco de dietas y ejercicios rigurosos, el individuo es proclive a sentirse culpable por desviarse, aunque sea mínimamente, de estas prescripciones y, por tanto, de autocastigarse por ello (sea vía la reducción de ingesta alimenticia o el aumento desmesurado de actividad física). Aunque el cristianismo sugiere ejercicios espirituales más que físicos, actualmente es posible distinguir estas prácticas como métodos de redención de los ya referidos desvíos.

De otro lado, el judaísmo, religión que se abre a entender la santidad de los alimentos, es estricta en la identificación de lo que es bueno y lo que es malo. Evidentemente, la prohibición judía de los alimentos y su interpretación literal del 
Levítico tienen más que ver con la concepción que tiene sobre el contrato con Dios y sobre las formas de distinguirse de las demás comunidades alrededor del mundo que con una cuestión de alcanzar ideales de belleza. Para los judíos, la alimentación es instrumental para servir a Dios y permite identificar a los verdaderos miembros de la comunidad, santificados por respetar estas prácticas culinarias.

Sin embargo, es posible identificar rasgos de estas prescripciones judías en la forma en que se concibe la alimentación occidental en la actualidad. Más que prohibiciones tajantes, el mercado busca orientar el consumo respecto a lo que es bueno y lo que es malo. Por temporadas se ha puesto de moda cortar el consumo de alimentos que contengan carbohidratos, azúcar y, más recientemente, la carne animal. Aunque podrían existir razones genuinas detrás de estas 'recomendaciones', en el fondo, el objetivo es alcanzar el ideal de belleza de delgadez por medio del excesivo control de la ingesta en el marco de la abundancia alimenticia existente.

Al igual que los judíos, a los individuos se les exige adscribirse a las cosas que se consideran buenas y la evidencia de esta disciplina es esa delgadez (Stearns, 2002). Si se es delgado, seguramente es porque se come bien y se ejercita lo suficiente. Esta podría constituir una de las principales lógicas articuladoras de la actualidad. De esta forma, el individuo sería capaz de ingresar a la comunidad de lo correcto, de lo agradable, de lo aceptable, de lo bello. La delgadez es el fin y el rito de nuestra sociedad.

Por último, la dietética islámica ofrece una visión interesante sobre los cuerpos ligeros y los cuerpos pesados. Sin embargo, quizá el aspecto más relevante de sus preceptos es el del control de las porciones: saber cuánto comer, así sea bueno o malo; la indigestión es parte de la experiencia de la vida y lo importante es saber entrenar al cuerpo. En esta línea, la dietética islámica hace énfasis en cómo a través de la alimentación es posible curar los cuerpos enfermos, poniendo en plano secundario a la medicina y la cirugía, elementos que deben utilizarse solo si los problemas no se solucionan por la vía alimenticia, no como en la actualidad, en que se han convertido en el medio de los "vagos" para acercarse a lo bello.

De esta forma, el problema central para el islam es la buena digestión, para lo cual hay que mantener el estómago liviano. Aunque se recomienda el ejercicio físico, el objetivo sigue siendo mantener un equilibrio, por lo que se penalizan los cuerpos muy trabajados o lánguidos. Todo en su punto, evitar la inflamación y el estiramiento del estómago. Así, los alimentos no son malos por naturaleza, sino que se debe calcular las porciones adecuadas para evitar que enfermen nuestros cuerpos. 
La observación de las porciones para el islam tiene más que ver con la simetría corporal y espiritual que con la concepción actual de contar calorías y permitirse una indulgencia mientras cualquier consumo ingrese y se reduzca del conteo general. No obstante, es así como actualmente se entienden estos conteos: no exceder de cierto gramaje y tipo de cocción. Se recomienda determinada cantidad de frutas y verduras de forma general, ignorando que cada cuerpo y metabolismo puede requerir soluciones diferentes, como lo veía el islam. Ahora, la dieta se guía por medio de libros genéricos vendidos a nivel mundial, sin siquiera tropicalizarlos conforme a los productos de las distintas regiones mundiales.

Como se ha visto, mientras las prescripciones religiosas se centran en definir qué y cómo se puede comer con el objetivo de servir mejor a Dios, actualmente, atestiguamos una serie de prácticas que buscan la consecución de un ideal de delgadez, para muchos inalcanzable. Aunque este tipo de cuerpos se posicionan como la definición de belleza tan recientemente como la segunda época del siglo $X X$, lo cierto es que las características de interconexión mundial han logrado que permee a lo largo de diversas regiones y culturas, posicionando un culto al cuerpo y su iglesia es el gimnasio.

La colonización de nuestras mentes, por parte de esta idea capitalista, ha implicado el creciente surgimiento de desórdenes alimenticios y mentales, manifestado en prácticamente todo individuo. Estar consciente de esto implica buscar las formas en que cada uno puede subvertirse ante estas demandas y crear espacios de paz mental y, sobre todo, verdadera salud; ejercicio que se vuelve difícil considerando un entorno lleno de influencers, publicidad y aplicaciones que buscan hacernos entrar en una lógica de belleza que enmascara, nuevamente, el poder del capital.

\section{Referencias bibliográficas}

Aamodt, S. (2016). Why Diets Make Us Fat: The Unintended Consequences of Our Obsession With Weight Loss. New York: Penguin Random House

Álvarez Solís, A. (2019). Introducción a la Dietética [Material del aula]. Ciudad de México, México: Universidad Iberoamericana. 
Anderson, J. (2011). "Vanity vs. Gluttony: Competing Christian Discourses on Personal Health". Journal of Applied Communication Research, (39)4, pp. 370-388.

Brierley, M., et al. (2016). "The Body and the Beautiful: Health, Attractiveness and Body Composition in Men's and Women's Bodies". PLOS One, (11)6, pp. 1-16. DOI: 10.1371/journal.pone.015672

De Aquino, T. (1998). “La gula”. En: Summa Theologica II, Ilae, c.148. Madrid: BAC.

Douglas, M. (1973). "Las abominaciones de Levítico". En: Pureza y peligro. Un análisis de los conceptos de contaminación y tabú. Madrid: Siglo XXI.

Eliasi, J. \& Dwyer, J. (2002). Kosher and Halal: Religious observances affecting. Dietary intake. Journal of the American Dietetic Association (102), 7, pp. 911-913.

Girard, R. (2009). La anorexia y el deseo mimético. Barcelona: Marbo.

Hipócrates. (1987). Sobre la dieta, Libro 1. Madrid: Gredos.

Hoverd, W. J. (2011). Gluttony and Sloth: The Moral Politics of Obesity Discourse. [Tesis Doctoral]. Wellington, Nueva Zelanda: Victoria University of Wellington.

Maimónides. (2016). "El régimen de la salud". En: Obras Médicas I. Madrid: Herder.

O'Neill, K. \& Silver, D. (2016). "From Hungry to Healthy. Simmel, Self-Cultivation and the Transformative Experience of Eating for Beauty". Food, Culture \& Society, (20)1, pp. 101-132.

Otsuki, D. (2016). "The Excessive Body and The Sickly Soul: Christian Nutritionists and Contemporary Gluttony". Relics, Remnants, and Religion: An Undergraduate Journal in Religious Studies, (2)1. Artículo 11. Recuperado de: http://soundideas. pugetsound.edu/relics/vol2/iss1/11

Plutarco. (2018). Cómo mantenerse sano. México: Me cayó el veinte.

Regenstein, J.M; Chaudry, M.M \& Regenstein, C.E. (2006) "The Kosher and Halal Food Laws". Comprehensive Reviews in Food Science and Food Safety (2)3. DOI: https://doi.org/10.1111/j.1541-4337.2003.tb00018.x

Stearns, P. (2002). Fat History: Bodies and Beauty in the Modern West. New York: New York University Pres.

Vigarello, G. (2011). "La revolución de la delgadez". En La metamorfosis de la grasa. Historia de la obesidad. Barcelona: Península. 